\title{
Filsafat Pendidikan Islam \\ Dalam Perspektif Alghazali Dan Ibnu Khaldun
}

Fathorrahman

STIT Aqidah Usymuni Sumenep

\begin{abstract}
In-depth, comprehensive, systematic and radical discussion of the educational problems above is the most appropriate alternative. The philosophical approach is very appropriate to unravel the tangled thread of the problem of education in

Indonesia, especially Islamic education. The reason is that the majority of Indonesian Muslims are still bound by the thought of liberalism and conservatism. So that Islamic education as a whole is divided

Pembahasan mendalam, menyeluruh, sistematis dan juga radikal terhadap problematika pendidikan di atas adalah alternatif yang paling tepat. Pendekatan filsafat sangat tepat untuk mengurai benang kusut problematika pendidikan di

Indonesia, khusunya pendidikan Islam. Pasalnya, masyarakat Indonesia yang mayoritas Muslim, masih saja terbelenggu oleh pemikiran antara liberalisme dan konservatisme. Sehingga pendidikan Islam secara kesuluruhan terbelah
\end{abstract}

\section{A. Mukaddimah}

Membincang masalah pendidikan seakan-akan tidak akan pernah ada habisnya. Mulai dari masalah kurikulum, profesionalisme guru, tawuran antar pelajar hingga anak didik yang gantung diri karena tidak mampu membayar biaya pendidikan. Indonesia yang terus memacu diri dan menyejajarkan kemajuannya dengan negara-negara lain kini malah terjebak dalam kungkungan kapitalisme pendidikan. Pendidikan yang pada dasarnya bervisi utama untuk mencerdaskan anak bangsa dan mengembangkan nalar kreatif dan nalar intelektual pada tahapan yang lebih tinggi malah berlomba-lomba mencetak anak didik sesuai orientasi pasar bukan lagi berorientasi keilmuan dan bakat anak didik. Alhasil lahirlah murid-murid tipe mechanic student yang diposisikan pada orientasi pasar namun kering wawasan keagamaannya alih-alih iman dan akhlaknya. Fenomena ini berjalin erat pula dengan para pengambil kebijakan yang merumuskan tujuan pendidikan secara dangkal dan pragmatis semata. 
Fenomena lain tentang rendahnya mutu pendidikan yakni terkait efektivitas, efisiensi dan standarisasi pengajaran. Secara umum, hal demikian menjadi masalah pendidikan di Indonesia. Selain kurang kreatifnya pendidik dalam membimbing siswa juga kurikulum yang sentralistik membuat potret pendidikan Indonesia semakin carut marut. Kurikulum hanya didominasi oleh kerja pemerintah saja tanpa memerhatikan situasi dan kondisi setiap lini masyarakat yang masingmasing memiliki kebutuhan yang berbeda-beda..

Selain itu, pendidikan Islam juga memiliki peran penting dalam membentuk karakter anak didik. Apalagi di era digitalisasi ini, gempuran teknologi berupa gadget perlahan menggerus dunia pendidikan utamanya moral anak didik. Tetapi yang paling urgen adalah bagaimana nilai-nilai moral yang telah ditanamkan pendidikan Islam tersebut mampu berperan sebagai kekuatan pembebasan dari himpitan teknologi, politik, hukum, kemiskinan, kebodohan, dan keterbelakangan sosial budaya dan ekonomi. Hal ini menunjukkan bahwa pendidikan Islam memiliki peran yang sangat penting dalam proses pembentukan individu yang yang tidak hanya cerdas, tapi juga berkepribadian yang baik serta memilliki pemahaman beragama yang tidak hanya dipahami tapi juga diterapkan dalam kehidupan

Maka kiranya membongkar, membedah (dekonstruksi) kemudian dilanjutkan dengan merekonstruksi terhadap bangunan pendidikan; kurikulum, media, metode pengajaran dan lain-lainnya adalah hal yang mutlak. Kalau tidak, maka kita akan tetap menjadi konsumerisme ideologi pendidikan Barat yang individualistik, pragmatis dan segala macam tetekbenge'. Atau kita akan "memakan" pemikiran yang ditawarkan oleh pendidikan yang marxis. Maka kita sungguh-sungguh kehilangan ruh pendidikan Islam yang sejati.

\section{B. Pengertian Filsafat Pendidikan Islam}

Filsafat pendidikan Islam terbentuk dari tiga kata, yakni filsafat, pendidikan dan Islam. Pengertian Filsafat Pendidikan berbeda dengan 
filsafat pendidikan Islam. Dengan penambahan kata Islam menunjukkan perbedaan dengan pengertian filsafat secara umum. Lebih lanjut kita bahas pengertian filsafat pendidikan Islam.

Secara harfiah, kata filsafat berasal dari kata Yunani yaitu philos yang berarti suka atau cinta, dan sophia yang berarti kebijaksanaan (Titus, 1984: 11). Teori lain mengatakan bahwa filsafat berasal dari kata Arab yakni falsafah. Kata Falsafah adalah bahasa Arab bentukan setelah bangsa Arab mengenal kata filsafat dari bangsa Yunani.

Meskipun demikian bukan berarti filsafat sebagai ilmu hakikat tidak ada dalam Al-Qur'an. Filsafat sebagai ilmu hakikat terdapat dalam alQur'an disebut dengan kata hikmah,al-hikmah, dan disebutkan dalam alQur'an sebanyak 20 ayat (Asy'arie,1992: 14).

Selanjutanya Titus (1984: 11) mengemukakan lima pengertian dari filsafat. Yaitu:

1. Filsafat adalah suatu sikap dan kepercayaan terhadap kehidupan yang diterima seara kritis.

2. Filsafat adalah suatu proses kritik atau pemikiran terhadap kepercayaan dan sikap yang sangat kita junjung tinggi.

3. Filsafat adalah usaha untuk mendapatkan gambaran yang luas.

4. Filsafat adalah analisa logis dari bahasan serta penjelasan tentang arti kata dan konsep.

5. Filsafat adalah sekumpulan problema-problema yang langsung mendapat perhatian dari manusia dan yang dicarikan jawabannya oleh ahli filsafat. ${ }^{1}$

Setelah mengetahui makna dan arti kata filsafat, selanjutnya pembahasan yang harus dijelaskan dalam penulisan ini adalah tentang pendidikan.

Kata pendidikan dalam kamus umum bahasa Indonesia adalah perbuatan (hal, cara, dan sebagainya) mendidik. Selain kata pendidikan, dalam bahasa Indonesia terdapat pula kata pengajaran. Kata pengajaran

${ }^{1}$ Titus, H. Arold, 1984. Perosalan-persoalan Filsafat. Jakarta: Bulan Bintang, hlm. 11 
adalah cara mengajar atau pengajaran, memberi pengetahuan atau pelajaran. ${ }^{2}$ Dalam bahsa Inggris kata pendidikan sering diartikan dengan education, sedangangkan pengajaran diartikan teaching.

Masih dalam kebahasaan, kata Tarbiyah mengandung arti memelihara, membesarkan, mendidik, sekaligus mengandung makna mengajar. Sedangkan Naquib al-Attas menambahkan bahwa selain kata Tarbiyah dan Ta'lim juga bermakna ta' dib yang ada hubungannya dengan adab. ${ }^{3}$ Al-Attas mempertahankan kata ta'dib untuk konsep pendidikan Islam, bukan tarbiyah, dengan alasan bahwa dalam istilah ta' dib mencakup wawasan ilmu dan amal yang merupakan esensi pendidikan Islam. ${ }^{4}$

Yang ketiga adalah kata Islam, lebih tepatnya sebagai istilah generiknya: "al-Islam" dibahas dalam pengertian asalnya, yaitu "sikap tunduk-patuh dan taat-pasrah kepada Tuhan yang meliputi seluruh alam dan al-islam universal inilah yang merupakan satu-satunya ajaran ketundukan atau din yang dibenarkan dan diterima oleh Tuhan yang Maha Esa. Para Nabi adalah Muslim, hanya saja masalah kebahasaan atau peristilahan dalam bahasa Arab yang berbeda. Karena itu mereka sebagai orang-orang muslim dan ajaran atau agama mereka sebagai al-islam tetap benar dan dibenarkan. ${ }^{5}$

Kitab Suci memberikan berbagai ilustrasi tentang ketundukan, ketaatan dan kepasrahan alam semesta kepada Tuhan:

"Matahari dan bulan beredar dengan perhitungan (yang pasti), dan bintang-bintang serta pepohonan semuanya bersujud" (al-Qur'an, Fushshilat: 11).

${ }^{2}$ Poerwadarminta, WJS, 1991. Kamus Umum Bahasa Indonesia.Jakarta: Balai Pustaka, hlm. 250

${ }^{3}$ Faisal, A. Yusuf, 1994. Pokok pokok pikiran tentang Ilmu Pendidikan.Jakarta, hlm. 19

${ }^{4}$ Al-attas, Naquib, 1994. Konsep Pendidikan Islam. Bandung:Mizan, hlm. 60.

${ }^{5}$ Madjid, Nurcholish, 1998. Passing Over: Melintasi Batas Agama. Jakart: Misan Bandung, hlm. 17. 
Filsafat pendidikan menurut al-Syaibani dalam bukunya falsafah al-Tarbiyah al-islamiyah mengartikan bahwa aktivitas pikiran yang teratur yang menjadikan filsafat tersebut sebagai jalan untuk mengatur , menyelaraskan dan memadukan proses pendidikan. ${ }^{6}$

Imam Barnadib mendefinisikan filsafat pendidikan sebagai ilmu yang pada hakekatnya merupakan jawaban dari pertanyaan-pertanyaan dalam bidang pendidikan. ${ }^{7}$

Sedangkan filsafat pendidikan Islam merupakan suatau kajian secara filosofis mengenai berbagai masalah yang terdapat dalam kegiatan pendidikan yang didasarkan pada al-Qur'an dan Hadist sebagai sumber primer, dan pendapat para ahli, khususnya para filosof muslim sebagai sumber sekunder. Selain itu filsafat pendidikan Islam dapat pula dikatakan suatu upaya berpikir secara mendalam, sistematik, radikal, dan universal tentang masalah pendidikan, seperti anak didik, guru, kurikulum, metode, lingkungan pendidikan dengan menggunakan al-qur'an dan hadist sebagai acuan sumbernya.

Menurut Asy-syaibani, filsafat pendidikan Islam pada hakekatnya adalah:

- Pelaksanaan pandangan dan kaidah filsafat Islam yang diterapkan di bidang pendidikan.

- Aktifitas pemikiran yang teratur, selaras dan terpadu dalam upaya menjelaskan nilai-nilai dan tujuan yang hendak dicapai, bersumber dari anugerah Tuhan Yang Maha Esa.

\section{Ruang Lingkup Filsafat Pendidikan Islam}

Menurut Muzayyin Arifin mempelajari filsafat pendidikan Islam berarti memasuki arena pemikiran yang mendasar, sistematik, logis dan menyeluruh (universal) tentang pendidikan, yang tidak lain hanya

\footnotetext{
${ }^{6}$ Djalaluddin, 1997. Filsafat Pendidikan, Jakarta: Gaya Media Pratama, hlm. 13

${ }^{7}$ Barnadib, Imam, 1997. Filsafat Pendidikan, Metode dan Praktek. Yogyakarta: Andi, hlm. 7
} 
dilatarbelakangi oleh pengetahuan Islam saja, melainkan menuntut kita untuk mempelajari ilmu-ilmu yang relevan. Pendapat ini menunjukkan bahwa ruang lingkup filsafat pendidikan Islam adalah masalah-masalah yang terdapat dalam kegiatan pendidikan, seperti masalah tujuan pendidikan, masalah guru, kurikulum, metode dan lingkungan. Bagaimanakah semua masalah itu disusun, tentu saja harus ada pemikiran yang melatarbelakangi. Pemikiran yang melatarbelakangi disebut filsafat pendidikan Islam. Karena itu dalam mengkaji filsafat pendidikan Islam seseorang akan diarahkan untuk memahami konsep tujuan pendidikan, konsep guru yang baik, konsep kurikulum, dan seterusnya yang dilakukan secara mendalam, sistematik, logis, dan radikal serta universal berdasarkan tuntutan dan tuntunan ajaran Islam, khususnya al-Qur' an dan Hadist. ${ }^{8}$

\section{Kegunaan Filsafat Pendidikan Islam}

Para ahli dibidang ini telah banyak meneliti secara teoritis mengenai kegunaan filsafat pendidikan Islam. Omar Muhammad al-Toumy al-Syaibany seperti yang dikutip oleh Abuddin Nata mengemukakan tiga manfaat dari mempelajari Filsafat pendidikan Islam tersebut sebagai berikut:

1. Filsafat pendidikan Islam dapat menolong para perancang pendidikan dan orang-orang yang melaksanakannya dalam suatu negara untuk membentuk pemikiran sehat terhadap proses pendidikan.

2. Filsafat pendidikan dapat menjadi asas yang terbaik untuk penilaian pendidikan dalam arti yang menyeluruh. Penilaian pendidikan itu dianggap persoalan yang perlu bagi setiap pengajaran yang baik. Dalam pengertian yang baru, penilaian pendidikan meliputi segala usaha dan kegiatan yang dilakukan oleh sekolah, institusi-institusi pendidikan secara umum untuk mendidik angkatan baru dan warga negara dan segala yang berkaitan dengan itu.

\footnotetext{
${ }^{8}$ Nata, Abuddin, 2001. Filsafat Pendidikan Islam. Jakarta: Logos Wacana Ilmu, hlm. 16.
} 
3. Filsafat pendidikan Islam akan menolong dalam memberikan pendalaman pikiran bagi faktor-faktor spiritual, kebudayaan, sosial, ekonomi, dan politik di negara kita.

\section{E. Pemikiran Filsafat Pendidikan Islam dalam Pandangan Para Filosof}

1. Pemikiran Pendidikan Al-Ghazali

a. Biografi Al-Ghazali

Nama lengkapnya adalah Abu Hamid Muhammad bin Muhammad Al-Ghazali. Ia lahir tahun $450 \mathrm{H}$, bertepatan dengan 1059 M. di Ghazaleh, suatu kota kecil yang terletak di Tus (Khurazan). Dan wafat di Tabristan wilayah propinsi Tus tahun 505, tepatnya 1 Desember 1111M.

Al-Ghazali memulai pendidikannya di wilayah kelahirannya, selanjutnya ia pergi ke Nisyafur dan Khurazan yang pada waktu itu kedua kota tersebut sebagai pusat ilmu pengetahuan yang terpenting di dunia Islam. Di kota Nisyafur inilah Al-Ghazali berguru kepada Imam al-Haramain Abi al-Ma'ali al-Juwainiy, seorang ulama' yang bermazhab Syafi'i yang pada saat itu menjadi guru besar di Nisyafur.

Pelajaran yang dipelajari Al-Ghazali adalah logika, hukum Islam, filsafat, logika, sufisme dan ilmu alam.

b. Beberapa karya tulis yang dipengaruhi oleh ilmu yang telah diajarinya adalah Ghayah al-Maram fi Ilm al-Kalam, Ihya' Ulumuddin, al-Musytasyfa, Maqasida al-Falasifa, Tahafu alfalasifa. Beberapa gelar yang beliau dapatkan adalah Hujjatul Islam, Syaikh al-Sufiyyin dan Imam al-Murabin.

c. Pemikiran pendidikan Al-Ghazali

1. Peranan pendidikan

Bila dipandang dari segi filosofis, Al-Ghazali adalah penganut paham idealisme yang konsekuen terhadap agama sebagai dasar pandangannya. Dalam masalah pendidikan AlGhazali lebih cenderung berpaham empirisme. Hal ini antara 
lain disebabakan karena ia sangat menekankan pengaruh pendidikan terhadap anak didik. Menurutnya pengaruh anak tergantung pengaruh orang tuanya. Hati seorang anak itu bersih, suci, laksana permata yang sangat berharga, sederhana dan bersih dari gambaran apa pun. Sebagaimana sabda Nabi: setiap anak lahir dalam keadaan bersih (Fitrah), kedua orang tuanyalah yang menyebabkan anak itu menjadi penganut Yahudi, Nasrani atau Majusi (HR. Muslim).

2. Tujuan pendidikan

Menurutnya, tujuan pendidikan tidak lain hanya mendekatkan diri pada Tuhan. Bukan untuk mencari kedudukan, kemegahan, kegagahan atau untuk menghasilkan uang sebanyak-banyaknya. Karena jjika tujuan pendidikan diarahkan bupakan pada mendekatkan diri pada Allah, akan dapat menimbulkan kebencian, kedengkian, dan permusuhan. AlGhazali menegaskan bahwa pencarian ilmu dalam berbagai bidang pada dasarnya sebagai tangga untuk mencapai ma'rifatullah. ${ }^{9}$

3. Pendidik

Ciri-ciri pendidik yang boleh melaksanakan pendidikan adalah:

a) Guru harus mencintai muridnya seperti mencintai anak kandungnya sendiri.

b) Guru jangan mengharap upah sebagai tujuan utama dari pekerjaan mengajarnya.

c) Guru harus mengingatkan muridnya agar tujuannya bukan unutk kebanggaan.

d) Guru harus mendorong agar mencari ilmu yang bermanfaat.

e) Guru sebagai teladan bagi murid-muridnya.

9 Achmadi, 2005. Ideologi Pendidikan Islam:Paradigma Humanisme Teosentris. Yogyakarta: Pustaka Pelajar, hlm. 146 
f) Guru harus memberikan pelajaran yang sesuai dengan tingkat kemampuannya.

g) Guru harus mengamalkan apa yang diajarkannya.

h) Guru harus memahami minat, bakat dan jiwa anak didiknya.

i) Guru harus dapat menanamkan keimanan ke dalam pribadi anak didiknya.

4. Murid

Bagi murid dikehendaki hal-hal sebagai berikut:

a) Memuiliakan guru dan bersikap rendah hati dan tidak takabur.

b) Satu bangunan yang saling membantu, menolong dan kasih sayang.

c) Tidak mempelajari bernagai mazhab yang dapat menimbulkan kekacauan dalam pikiran.

d) Mempelajari tidak hanya belajar satu ilmu saja.

5. Kurikulum

Ia membagi ilmu pada yang terlarang dan yang wajib dipelajari.

a) Ilmu yang tercela. Contoh, ilmu sihir, Nujum, perdukunan. Ilmu ini tidak ada manfaatnya di dunia dan akhirat.

b) Ilmu yang terpuji. Contoh ilmu Tauhi dan Agama. Ilmu ini membawa pada kesucian diri, rendah hati, tawadu' dan sangat bermanfaat.

2. Ilmu yang terpuji dalam taraf tertentu, dan tidak boleh diperdalam. Contoh filsafat. Karena ilmu ini membawa kegoncangan keimanan. ${ }^{10}$

3. Pemikiran Pendidikan Ibnu Khaldun

a. Biografi Ibnu Khaldun

Ia berasal dari keluarga aristokrat, politisi dan intelektual. Ia lahir 1332 di Tunisia. Oleh ayahnya diberi nama Abdur Rahman

${ }^{10}$ Nata, Abuddin, 2001. Filsafat Pendidikan Islam. Jakarta: Logos Wacana Ilmu, hlm. 166 
abu Zayd ibn Muhammad ibnu Khaldun. Umur 20 tahun ia sudah bekerja sebagai sekretarsi sultan Fez di Maroko. Kemudian menyebrang ke Spanyol bekerja di Granada sebagai mediator dan dalam waktu yang bersamaan juga ditawari pekerjaan di Sevilla. Pada akhirnya ia kembali ke Afrika karena menimbulkan iri hati perdana menteri di Granada.

Di Afrika sendiri terjadi pergolakan sehingga Ibnu Khaldun mengembara ke Aljazair, disana ia memimpin perang. Kemudian ia mengembara lagi ke Mesir, karena sudah terkenal dengan reputasinya ia menjadi guru dan kemudian menjadi Ketua mahkamah Agung. Setelah berhaji Ibnu Khaldun tinggal di Kairo bekerja dibawah kepemimpinan Dinasti Mamluk. Tak lama kemudian ia menjadi mediatorperdamaian dengan Timur Lenk, namun setelah perundingan, justru Timur Lenk berhasil menghancurkan Damaskus. Ibnu khaldun mundur beserta beberapa orang terkemuka lainnya tinggal di Mesir untuk menjadi Ketua Mahkamah Agung sampai beliau meninggal tahun1.406 dalam usia 74 Tahun.

b. Konsep pendidikan Ibn Khaldun

1) Pandangan tentang manusia didik

Ia bepandangan bahwa manusia tidak terlalu menekankan pada segi kepribadiannya, sebagaimana yang selalu dibicarakan oleh para filosof. Ia lebih banyak melihat manusia dalam hubungannya dan interaksinya dengan kelompok-kelompok yang ada di masyarakat. Dalam konteks inilah ia sering disebut sebagai pendiri sosiologi dan antropologi.

2) Pandangan tentang ilmu

Ia membaginya menjadi tiga:

a. Ilmu lisan

b. Ilmu naqli

c. Ilmu aqli 
3) Metode Pengajaran

Menurutnya, mengajarkan ilmu pengetahuan kepada pelajar hanyalah akan bermanfaat apabila dilakukan dengan berangsur-angsur, sedikit demi sedikit dan setahap demi setahap.

4) Spesialisasi

Menurut Ibnu Khaldun, orang yang mendapat keahlian dalam salah satu pertukangan, jarang sekali menjadi ahli pada pertukangan lainnya, misalnya tukang jahit. Hal ini disebabkan karena sekali seseorang telah menjadi ahli dalam menjahit sehingga keahliannya tertanam berurat berakar dalam jiwanya, maka setelah itu ia tidak akan ahli dalam pertukangan kayu dan batu. Kecuali apabila keahlianya yang pertama belum tertanam dengan kuat dan belum memberi corak terhadap pemikirannya. ${ }^{11}$

Dengan demikian, filsafat pendidikan Islam melampaui hal-hal dan nilai-nilai yang selalu bersifat absolut. Tidak ada konsep yang sakral atau prinsip yang abadi. Seiring berjalannya waktu, konsep dan prinsip yang menjadi landasan bagi pelaksanaan pendidikan selalu bias dikritisi dan dievaluasi. Di level inilah filsafat pendidikan Islam bekerja. Atau dengan kata lain filsafat pendidikan Islam berfungsi sebagai norma pendidikan. ${ }^{12}$

Era modernisasi, globalisasi yang penuh "bunga-bunga" intrik sepatutnya dikritisi dan dielaborasi dengan para filosof Muslim yang merupakan ilmuan yang tak pernah tertandingi. Dialog para filosof Muslim terdahulu dengan era digitalisasi adalah mutlak untuk mengembalikan kejayaan pendidikan Islam. Juga menjadi keniscayaan untuk mengambil hikmah, serta manfaat di zaman“sensasi” saat ini.

\footnotetext{
${ }^{11}$ Nata, Abuddin, 2001. Filsafat Pendidikan Islam. Jakarta: Logos Wacana Ilmu, hlm. 178 .

${ }^{12}$ Riyadi, Ahmad Ali, FilsafatPendidikan Islam, (Yogyakarta: PenerbitTeras, 2010), hlm. 5
} 
Pendidikan kita, Indonesia, harus bersih dari anasir-anasir Barat yang notabene menjauhkan kita dari religiusitas sehingga menjadi bangsa yang "moderat" dan juga harus menghindari pemikiran radikal karena antiprogres dan perkembangan peradaban. Di sinilah pendidikan kearifan lokal harus bicara! Artinya, pemikiran, kreativitas yang dimiliki bangsa kita juga harus diperhitungkan juga.

Dengan demikian, melalui konsep pendidikan Islam klasik, pendidikan Islam mengharap dan mendambakan terwujudnya Insan Kamil. Yaitu dimensi esoterik-vertikal yang intinya tunduk patuh kepada Allah SWT dan dimensi eksoterik-horizontal, yang intinya membawa misi keselamatan bagi lingkungan sosial alamnya dan juga sebagai manusia yang seimbang antara kualitas fikir, dzikir, dan 'amal.

\section{F. Penutup}

Khazanah pemikiran para Filosf Muslim yang berabad-abad terkubur, sepatutnya kita membongkar lagi untuk kepentingan dialog. Dialogis terdahulu-sekarang adalah suatu keharusan! Kalaut idak, maka kita akan kehilangan ruh pendidikan kita.

Sehingga para cendekiawan Muslim klasik tidak hanya jaya pada zamannya, tapi juga memberikan kontribusi yang bermanfaat bagi pendidikan Islam saat ini. Umat sangat membutuhkan pendidikan yang out-put-nya menjadi manusia yang Insan Kamil (manusia yang sempurna) di mata dunia dan juga sempurna di "mata" Allah SWT. Wallahu A'lam bi al-showaf.

\section{DAFTAR PUSTAKA}

Achmadi, 2005. Ideologi Pendidikan Islam:Paradigma Humanisme Teosentris. Yogyakarta: Pustaka Pelajar.

Al-attas, Naquib, 1994. Konsep Pendidikan Islam. Bandung:Mizan 
Asy'arie, Musa, 1991. Filsafat Islam:Kajian Ontologis, Epistemologis, Aksiologis, Historis, Prospektif. Editor Irma fatimah Arifin, H.M. FilsafatPendidikan Islam, (Jakarta: BumiAksara, 1993), hlm. xii

Al-Qur'an Depag

Barnadib, Imam, 1997. Filsafat Pendidikan, Metode dan Praktek. Yogyakarta: Andi

Djalaluddin, 1997. Filsafat Pendidikan, Jakarta: Gaya Media Pratama

Faisal, A. Yusuf, 1994. Pokok pokok pikiran tentang Ilmu Pendidikan.Jakarta.

Madjid, Nurcholish, 1998. Passing Over: Melintasi Batas Agama. Jakart: Misan Bandung

Nata, Abuddin, 2001. Filsafat Pendidikan Islam. Jakarta: Logos Wacana Ilmu.

Poerwadarminta, WJS, 1991. Kamus Umum Bahasa Indonesia.Jakarta: Balai Pustaka.

Riyadi, Ahmad Ali, FilsafatPendidikan Islam, (Yogyakarta: PenerbitTeras, 2010), hlm. 5

Titus, H. Arold, 1984. Perosalan-persoalan Filsafat. Jakarta: Bulan Bintang. 